Article

\title{
Particle Flow Characteristics and Transportation Optimization of Superfine Unclassified Backfilling
}

\author{
Ke-ping Zhou ${ }^{1,2}$, Rugao Gao ${ }^{1,2, *}$ and Feng Gao ${ }^{1,2, *}$ \\ 1 College of Resources and Safety Engineering, Central South University, Changsha 410083, China; \\ 128224@csu.edu.cn \\ 2 Hunan Key Laboratory of Mineral Resources Exploitation and Hazard Control for Deep Metal Mines, \\ Changsha 410083, China \\ * $\quad$ Correspondence: gaorgcsu@csu.edu.cn (R.G.); 209132@csu.edu.cn (F.G.); Tel.: +86-158-7429-0401 (R.G.)
}

Academic Editor: Abbas Taheri

Received: 21 October 2016; Accepted: 4 January 2017; Published: 6 January 2017

\begin{abstract}
In order to investigate the high volume fraction problem of the solid phase in superfine unclassified backfilling pipeline transportation, characteristic parameters were obtained by fitting to test data with an R-R particle size distribution function; then, a Euler dense-phase DPM (Discrete phase model) model was established by applying solid-liquid two-phase flow theory and the kinetic theory of granular flow (KTGF). The collision and friction of particles were imported by the UDF (User-define function) function, and the pipeline fluidization system, dominated by interphase drag forces, was analyzed. The best concentration and flow rate were finally obtained by comparing the results of the stress conditions, flow field characteristics, and the discrete phase distributions. It is revealed that reducing the concentration and flow rate could control pressure loss and pipe damage to a certain degree, while lower parameters show negative effects on the transportation integrity and backfilling strength. Indoor tests and field industrial tests verify the reliability of the results of the numerical simulations. Research shows that the model optimization method is versatile and practical for other, similar, complex flow field working conditions.
\end{abstract}

Keywords: backfilling pipeline; superfine tailings; dense DPM model; numerical simulation; particle size distribution

\section{Introduction}

Solid-liquid, two-phase flow theory is widely applied in industry, especially in the chemical and energy industries, etc. The development of pipeline technology reached a substantive stage in the 1990s, and a great deal of feasibility analyses on mine material slurry pipeline transportation has been done during this period, laying a foundation for the application of slurry pipeline transportation technology [1]. Researchers carried out a great deal of research on pipeline transportation mechanisms and multiphase flow theory [2-5] Sommerfeld calculated particle group movement using the Lagrange method in 1998; Hewitt constructed a wall abrasion test for backfilling pipelines in 2009; Buffo A established a model to study the gas-liquid, two-phase flow in a stirred tank in 2012; Boger D V researched slurry rheological properties and environmental effects in mining engineering in 2013; other progress has also been made. Research methods are mostly limited in areas of uniform field theory, lacking consideration on particle distribution and interactions, which has resulted in fewer research achievements on the dense particle flow characteristics of backfilling slurry. With the improvement of beneficiation precision, ultrafine particle sizes and high concentrations are regarded as the development objectives of backfilling transportation. When the slurry concentration is high and great deal of fine particles exist, the relationship between the shear rate and shear stress of backfilling slurry presents nonlinear characteristics; as a kind of non-Newtonian fluid [6]. At present, 
tphe mixture model and conventional Euler model are usually used in numerical simulations on two-phase flows $[7,8]$. The multiphase mixed flow field is averaged in these methods, with less analysis on the movement and function of discrete phases.

Two-phase particle flow mechanics theory, combining the characteristics of a pipeline transportation fluidization system, was used in this research. The high volume fraction problem of the solid phase was analyzed using the Euler DDPM (Dense discrete phase model) particle flow model of the Fluent software platform [9]. Backfilling ultrafine particle distribution characteristics were imported into the initial parameters of backfilling transportation using the Rosin-Rammler particle size distribution function. The model was established based on the kinetic theory of granular flow (KTGF) [10,11], considering the interactions between dispersed phase particles. The interphase drag model was refined by user-defined functions during the process of calculation. Subsequently, the conveying parameters of fine optimization are subtly implemented. In later work, indoor experiments and field transportation were carried out, verifying the reliability of the model simulation results. This approach is an innovative attempt in mining engineering. The problem of high volume fractions of particle flow in a filling pipeline was considered in the self-defined model; the analysis mode on the pressure field and velocity field of the conventional two-phase flow homogenization method was changed for particle flow-driven fluidization analyses and parameter optimization. Mutual verification between numerical simulations and indoor small test results was realized. The results provide some basis for flow field calculations and parameter optimization in mine-filling conveying.

\section{Research Objectives and Methods}

\subsection{Project Description}

The research object is located in the Mercury Cave gold mine, Guizhou. The mine production capacity will reach 450,000 tons/year when the third-stage project is put into production (ore of high grade and reserves). Short-hole pillar-stall stopping and fill stopping have always been major mining methods, and artificial pillars are adopted underground in order to recycle more resources. The residual goaf volume in the mine is from $80,000 \mathrm{~m}^{3}$ to $100,000 \mathrm{~m}^{3}$. In order to protect the Earth's surface, improve ore recovery, and recycle backfill tailings, the Zijin Mining Company was ready to upgrade the backfilling thick facilities and backfilling gravity systems. The planning of the backfilling process of the Mercury Cave gold mine is shown in Figure 1. The mine filling system adopts a vertical tailing bin to complete the dewatering of unclassified tailings, a double-shaft vane type agitator and high-speed mixer are used to prepare the filling material for the pipeline gravity transport. Cement-dedicated transport vehicles were used to feed the cement warehouse. Tailings were transported to the vertical tailing bin (shown in the figure) for high-pressure gas manufacturing slurry after being processed by the oil isolation pump. After sedimentation, the high-density bottom flow was mixed with the transported cement by a screw feeder. After being added to water, the mixture was transported to a double-shaft vane type mixer and high-speed mixer for double-stage, strong stirring. Ultimately, the slurry is imported to the industrial piston pump for gravity transmission. The entire process is under the control of flow meters and electric pinch valves. Electronically-controlled variable frequency regulation was performed, based on parameters, such as flow, concentration, and cemented-tailing ratio. 


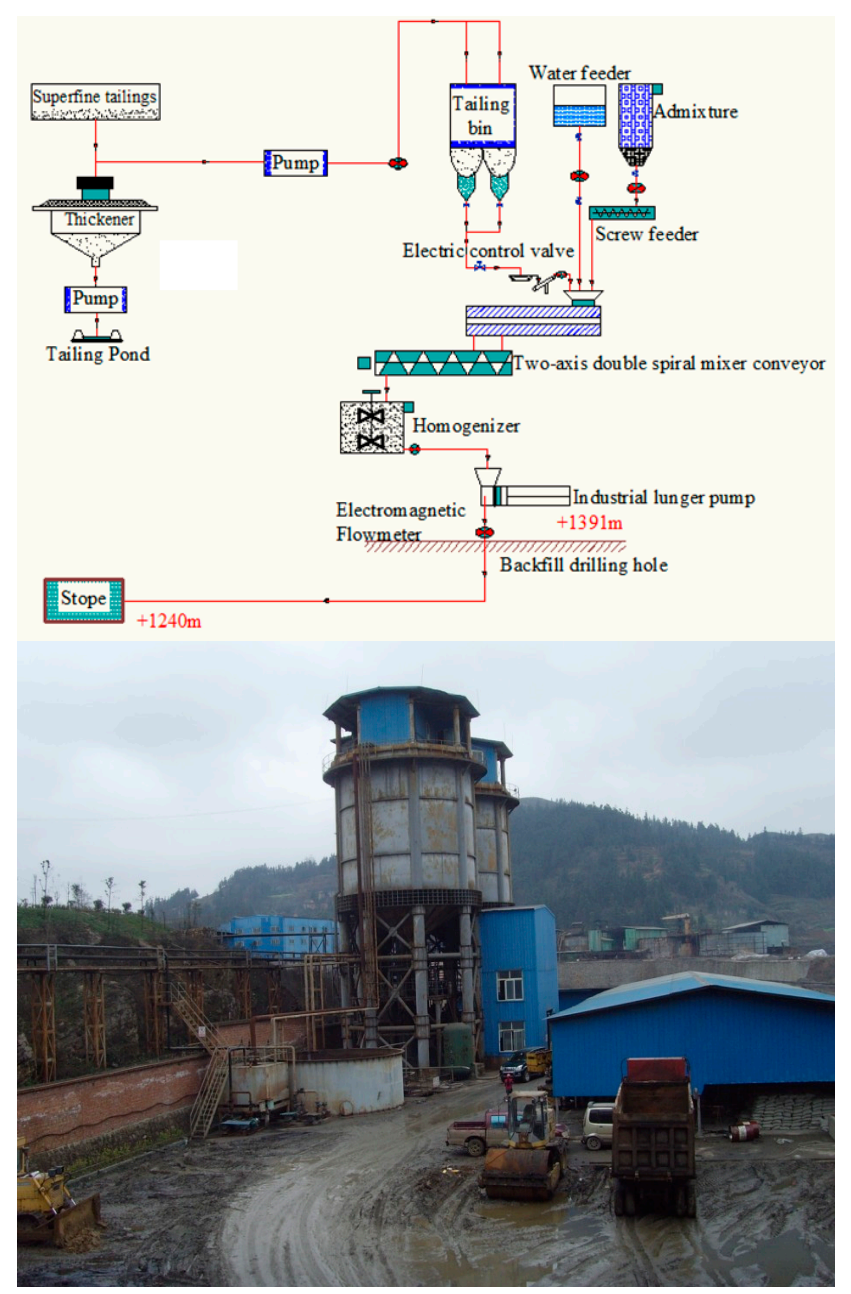

Figure 1. Backfilling technological process and industrial site.

\subsection{Model Computational Domain}

In order to improve mine backfilling transportation systems, the methods of experimentation and numerical simulation were used in transportation parameters optimization. Model preprocessing was prepared in the ICEM CFD (The Integrated Computer Engineering and Manufacturing code for Computational Fluid Dynamics) module of the Workbench platform, with the actual size being reserved. A backfilling industrial site was set up on the mine surface $(1391 \mathrm{~m})$, filling drills extended to the main production phase $(1240 \mathrm{~m})$ with a pipe diameter of $0.1 \mathrm{~m}$. Filling time value was set to 3, based on previous survey results. The pipeline diameter was kept at a vertical level of $150 \mathrm{~m}$, horizontal length of $300 \mathrm{~m}$, having a $90^{\circ}$ elbow, and a curvature radius of $0.3 \mathrm{~m}$. The flow direction was set as baseline for unstructured mesh generation; a body-fitted grid was used in the elbow branch in order to improve convergence precision. The composition of the slurry included water $\left(25^{\circ} \mathrm{C}\right)$ as the continuous phase, with circular backfilling as the discrete particle phase. The simulation employs the full pipe flow calculation.

The piping erosion effect is different from that of the solid-liquid two-phase uniform flow of the conventional Euler model because of slurry particles discreteness, thus, the coupling solving calculation was based on the DDPM model and CFD method [12,13]. The dense molecular motion theory proves that collisions always exist between solid particles in process of movement; thus, granule impact must be considered in dense particle flow. 


\subsection{Particle Flow Distribution}

The superfine tailing field sampling was derived from dry cakes in filter press of the concentrating plant. Samples were preprocessed in a BGZ-146 electro-thermostatic blast oven in order to avoid the loss of superfine particles. A JM-A20002 electronic balance, with precision $0.01 \mathrm{~g}$, was used for weighing. Tailings were dried at $105^{\circ} \mathrm{C}$ for $6 \mathrm{~h}$ and then were removed for weighing; afterwards, the procedure was repeated every hour until the quality was stable. The backfills in the Mercury Cave gold mine showed a minor diameter and high viscosity. Samples needed to be rolled and uniformly mixed, repeatedly, in order to restore original particle fineness; thus, the indoor liquid sample configuration work could be carried out. The liquid samples were divided into two groups, with a total of ten copies. Particle size distribution was measured using the densimeter method, shown in Figure 2c.

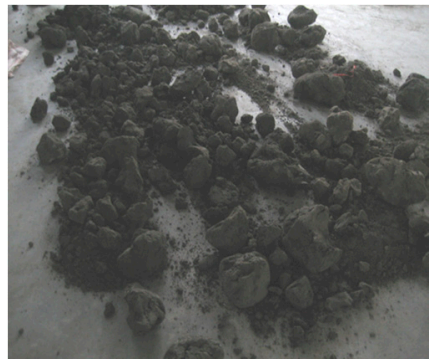

(a) field sampling

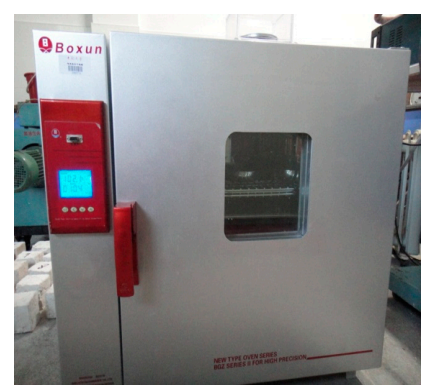

(b) drying procedure

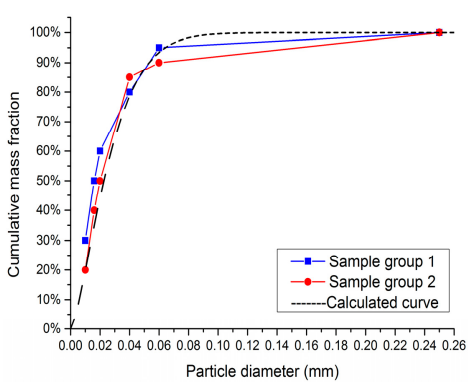

(c) particle size distribution

Figure 2. Backfilling materials sampling and particle size test.

It can be clearly observed from the results of particle size analyses that the proportion of particle diameters below $0.005 \mathrm{~mm}$ is more than $80 \%$ in both groups. This illustrates that the grinding degree of the mine is high, and most tailings discharged from the concentrating plant are typical superfine backfill. The physical and mechanical properties of the particles cannot simply described by "mean diameter" or "median diameter", as more sophisticated distribution parameters are also needed. Backfilling particle size distribution must be analyzed for particle flow calculations. Median diameters of the two sample groups are different, which caused a shortage in the "median diameter" method. Therefore, a kind of "morphological diameter" description method, based on the particle size of the Rosin-Rammler distribution function $[14,15]$ was applied in order to analyze the intrinsic relationship between various factors.

The Rosin-Rammler distribution is a form of cumulative distribution, its function expression is as follows:

$$
G=1-\exp \left[-a d^{n}\right]
$$

where $G$ is the particle cumulative percentage, $d$ is the backfilling particle size, $n$ is the distribution index, $n>1$, and $a$ is the size coefficient.

In order to analyze the relationship between the particle size distribution coefficient and the index, the derivative of Equation (1) is calculated. The probability density function is as follows:

$$
\frac{d G}{d(d)}=a n \exp \left[-a d^{n}\right] d^{n-1}
$$

There is a peak value for density function, the corresponding particle diameter is the morphological diameter, specified by $d_{0}$. Setting $d_{0}$ as the diameter parameter conforms to the essence of the function when considering the trend of the Rosin-Rammler distribution function. $d_{0}$ can be obtained through derivation of Equation (2):

$$
\frac{d^{2} G}{d(d)^{2}}=a n(n-1) d^{n-2} \exp \left[-a d^{n}\right]-a^{2} n^{2} d^{2 n-2} \exp \left[-a d^{n}\right]
$$


The second derivative is $d^{2} G / d\left(d_{0}\right)^{2}=0$, and we can obtain:

$$
\begin{gathered}
(n-1)-a n d_{0}^{n}=0 \\
d_{0}=[(n-1) / a n]^{1 / n}
\end{gathered}
$$

Equation (2) is the particle size at the peak of density function $\left(d_{0}\right)$. It shows that the morphological diameter is identified through index $n$ and coefficient $a$, which is more suitable for describing particle size distribution. Inserting Equation (4) into Equation (1), it can be written in the following form:

$$
G=1-\exp \left[-\frac{n-1}{n}\left(\frac{d}{d_{0}}\right)^{n}\right]
$$

Equation (5) illustrates the essence of the Rosin-Rammler particle size distribution function well because the exponential function is dimensionless. By fitting two groups of sample particle size distribution data using Equation (5), the results are shown in Figure 2c. The regression curve line is fit to the actual statistical data; fitting parameters $n$ and $d_{0}$ was used in consequent calculations.

\subsection{Calculation Equations}

The non-phase transformation movement process model is used in describing the Euler-Granular flow field. The continuity equation of the liquid phase is as follows:

$$
\frac{\partial}{\partial t}\left(\rho_{i} \alpha_{i}\right)+\nabla \cdot\left(\rho_{i} \alpha_{i} u_{i}\right)=m_{l s}
$$

where $i$ is the phase number; $\rho$ is the fluid density, $\mathrm{kg} / \mathrm{m}^{3} ; \nabla$ is the Laplacian; $\alpha$ is the fluid volume fraction, \%; $u$ is the fluid velocity, $\mathrm{m} / \mathrm{s}$; and $m_{l s}$ is the interphase mass transfer, the value is 0 in this model.

The improved model of Foerster et al. [16] is used for importing the collisions between particles. Supposing that we have particles $a$ and $b$, its normal unit vector $n_{0}$ and moment of inertia $I_{0}$ correspond to position vector $r_{a}, r_{b}$, then we can obtain:

$$
n_{0}=\frac{r_{a}-r_{b}}{\left|r_{a}-r_{b}\right|}, I_{0}=\frac{2}{5} m R^{2}
$$

The collision momentum between particles can be calculated according to Newton's second and third laws:

$$
\begin{gathered}
m_{a}\left(v_{a}-v_{a, 0}\right)=-m_{b}\left(v_{b}-v_{b, 0}\right)=J \\
\frac{I_{a}}{R_{a}}\left(\omega_{a}-\omega_{a, 0}\right)=\frac{I_{b}}{R_{b}}\left(\omega_{b}-\omega_{b, 0}\right)=-n_{0} \times J
\end{gathered}
$$

where $v$ is the velocity vector and $\omega$ is the rotation velocity vector.

Particle acceleration in solid-liquid two-phase flow is as follows:

$$
A_{s}=\frac{d u_{s}}{d t}=D_{s}\left(u_{l}-u_{s}\right)-\frac{1}{\rho_{s}} \nabla p+\left(1-\frac{\rho_{l}}{\rho_{s}}\right) g
$$

According to the theory of KTGF (the kinetic theory of granular flow), setting collisions between particles as spherical face collisions, the particle peudothermal temperature parameter $M$ is imported. The others are transient, inertia force, the pressure gradient force, and volume force. The momentum equation is as follows:

$$
\frac{\partial}{\partial t}\left(\rho_{i} \alpha_{i} u_{i}\right)+\nabla \cdot\left(\alpha_{i} \rho_{i} u_{i} u_{i}\right)=-\alpha_{i} \nabla p+\nabla \cdot \tau_{i}+\alpha_{i} \rho_{i} g+M_{i}
$$


Among them, the solid strength tensor is as follows:

$$
\begin{gathered}
\tau_{s}=-p_{s} I+2 \alpha_{s} \mu_{s} \bar{S}+\alpha_{s}\left(\lambda_{s}-\frac{2}{3} \mu_{s}\right)\left(\nabla \cdot u_{s}\right) I \\
\bar{S}=\frac{1}{2}\left(\nabla u_{s}+\nabla u_{s}^{T}\right)
\end{gathered}
$$

where $p$ is the static pressure, $\mathrm{Pa} ; p_{S}$ is the discrete phase internal normal stress, $\mathrm{Pa} \tau$ is the shear stress, $\mathrm{Pa} ; M$ is the momentum interaction, $\mathrm{kg} / \mathrm{m}^{2} \cdot \mathrm{s}^{2} ; \mu$ is the shear viscosity, $\mathrm{kg} / \mathrm{m} \cdot \mathrm{s} ; \lambda$ is the viscous coefficient, $\mathrm{kg} / \mathrm{m} \cdot \mathrm{s}$; and $I$ is the unit tensor.

\subsection{User-Defined Drag Force Model}

The Euler-Granular method was adopted in order to calculate phase tracking, and the DDPM model was used for solid-liquid two phase flow analysis, with a particle phase and a continuous phase, fully coupled, regardless of the heat exchange between in-phase and interphase. The standard $k-\varepsilon$ model was set for turbulence model, and the Syamlal-O'Brian drag model $[17,18]$ was adopted to calculate interphase momentum transmission:

$$
\begin{gathered}
\vec{F}_{\text {drag }}=\frac{C_{D} \operatorname{Re}_{s} \alpha_{l}}{24 v_{r, s}^{2}} \\
C_{D}=\left(0.63+\frac{4.8}{\sqrt{\operatorname{Re}_{s} / v_{r, s}}}\right)^{2}
\end{gathered}
$$

where $C_{D}$ is the drag coefficient; $\operatorname{Re}_{s}$ is the relative Reynolds number; and $v_{r, s}$ is the terminal velocity related to the solid phase.

In solid-liquid two-phase fluidization systems, an exchange coefficient formula is used to define the exchange coefficient and the shear stress of the solid phase:

$$
K_{s l}=\frac{18 \mu \alpha_{s} f}{d_{s}^{2}}
$$

To improve the calculation accuracy, it is necessary to control the minimum fluidization conditions. The correction coefficient of the solid phase terminal velocity $[19,20]$ was set according to the Syamlal-O’Brian drag model:

$$
v_{r, s}=0.5\left(A-0.06 \operatorname{Re}_{s}+\sqrt{\left(0.06 \operatorname{Re}_{S}\right)^{2}+0.12 \operatorname{Re}_{S}(2 B-A)+A^{2}}\right)
$$

where $A=\alpha_{l}^{4.14}$, when $\alpha_{l} \leq 0.85, B=0.8 \alpha_{l}^{1.28}$; when $\alpha_{l}>0.85, B=\alpha_{l}^{2.68}$.

In order to control the related correction coefficient and parameter boundary conditions, a solid-liquid two-phase drag model was compiled using the UDF function in Fluent. After the amended file of the drag force was generated, it was imported into numerical model. Part of the compilation content is as follows:

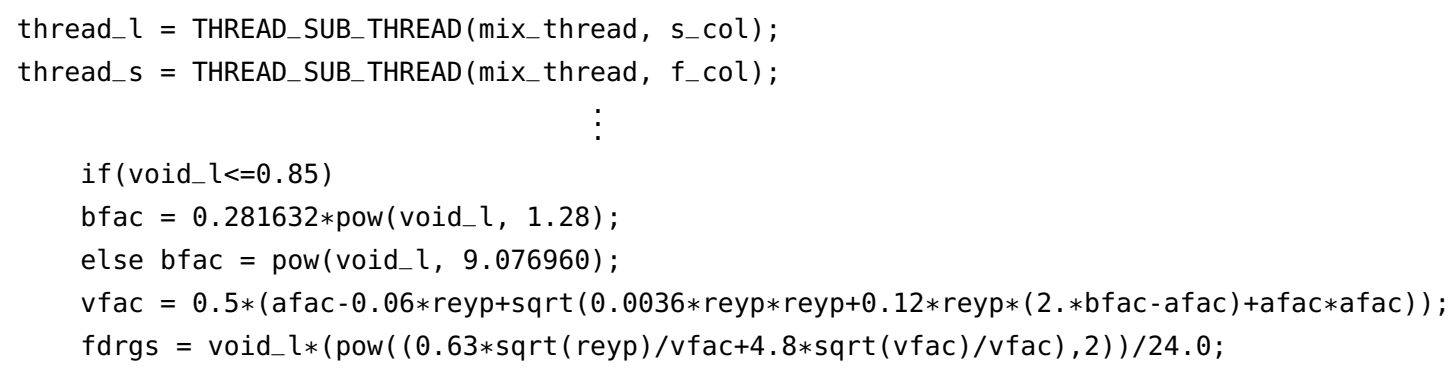


k_l_s $=(1$. -void_l $) *$ rho_s $*$ fdrgs $/$ taup;

reyp $=$ rho_l $2 *$ abs_ $\mathbf{V} *$ diam $2 / \mathrm{mu}_{-} \mathrm{l}$;

$c d=(24 . /($ reyp+SMALL $))+5.48 *$ pow $(($ reyp+SMALL $),-0.573)+0.36$;

void_l $=$ C_VOF (cell, thread_l);

el $=$ pow (void_l, -2.65$)$;

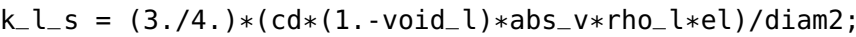

return k_l_s;

The dispersion of the calculating area and the control equation were handled using the finite volume method. The pressure coupling equations in the separation method and the semi implicit method (SIMPLE algorithm) were adopted for flow field numerical calculations [21]. The acceleration of gravity $-9.81 \mathrm{~m} / \mathrm{s}^{2}$ was included as the initial condition.

\section{Results and Discussion}

\subsection{Mechanism Description}

In the DDPM calculation process, the solid-liquid two-phase flow shows a fine interaction mechanism. As with most Euler methods, the continuous phase (water flow) sweeps all the grids in the form of quasi-uniform fields, evolving with the continuity equation of non-phase transitions. Unlike conventional methods, DDPM is compatible with continuous and discrete computations. Figure 3 shows the forces and motions of the particle phase during the calculation of the self-defined model in this study.

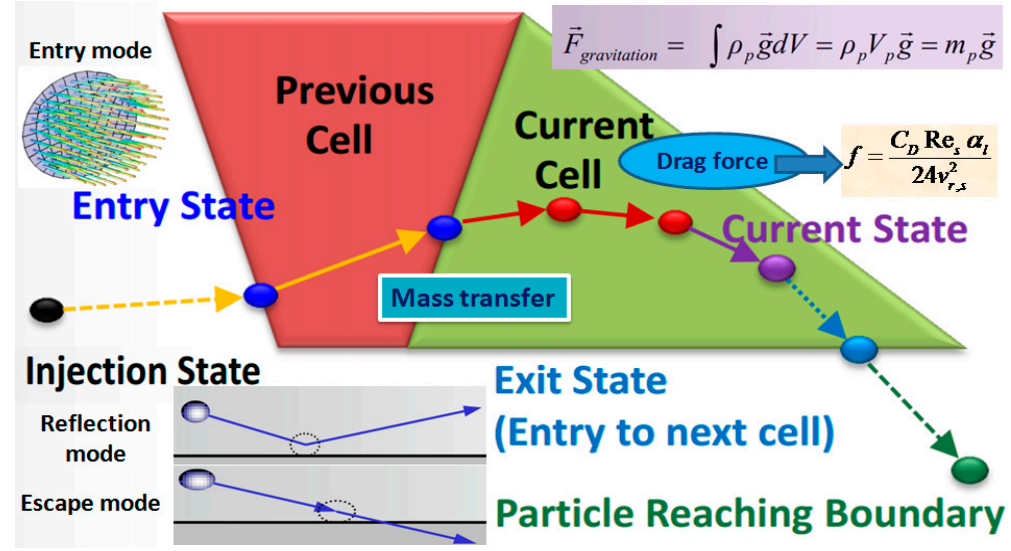

Figure 3. Particle phase movement mechanism.

In the granular particle tracing system, the tailings particles migrate in the model cell in three modes: The entry mode, the reflection mode, and the escape mode. In the incident phase, each element of the inlet is taken as a channel, and the tailing particles enter the flow field in the order of the Rosin-Rammler particle size distribution, as shown in Equation (5). The calculated value of particle size distributions with the calculated curve fitting in Figure 2c is $0.026 \mathrm{~mm}$. In the flow field, the particle-phase interaction is shown by the following formula:

$$
\frac{\partial}{\partial t}\left(\rho_{i} \alpha_{i} u_{i}\right)+\nabla \cdot\left(\alpha_{i} \rho_{i} u_{i} u_{i}\right)=-\alpha_{i} \nabla p+\nabla \cdot \tau_{i}+\alpha_{i} \rho_{i} g+M_{i}
$$


Figure 3 shows the flow field on the role of particles, which are mainly gravitational and interphase drag forces (interphase mass transfer as 0 ), as follows:

$$
m_{p} \frac{d \vec{u}_{p}}{d t}=\vec{F}_{\text {drag }}+\vec{F}_{\text {gravitation }}+\vec{F}_{\text {other }}
$$

The particles exhibit the reflection mode and escape mode at the cell junction. The reflection mode is the main form of particle phase interactions with wall units, which is characterized by the erosion of tailings particles or the dissipation of kinetic energy after sedimentation. This concentrated area tends to form erosion and sedimentation zones of the particle phase, which is obviously different from the homogeneous field simulation. When the particle flow is close to the boundary and the outlet of the flow field, the contact surface adopts the escape mode and the flow field enters the next action phase. Particle phase and kinematic characteristics are recorded in real time using a Granular tracking system in the form of node information feedback.

The results of pressure, flow field, and discrete phase distributions of the filling process with different slurry concentrations and flow rates were calculated using the UDF model of DDPM, as shown below.

\subsection{Concentration Analyses}

The slurry concentration was controlled within $50 \%$ 70\%, and slurry transportation flow within $50 \sim 70 \mathrm{~m}^{3} / \mathrm{h}$ to accord with the practical needs of mine filling system optimization. In the first stage of the simulation, the initial volume flow was fixed for $70 \mathrm{~m}^{3} / \mathrm{h}$, slurry transportation simulation analyses of different concentrations were conducted in this condition.

The internal pressure distribution for the slurry concentration was $70 \%$, and the conveying flow rate as $70 \mathrm{~m}^{3} / \mathrm{h}$, shown in Figures 4 and 5 . This shows that the flow field static pressure decreases step-by-step from entrance to the export, in addition to a certain degree of recovery at the elbow. The dynamic pressure is stable because of the traffic flow field. The maximum dynamic pressure appears at the center of the pipe, but is relatively concentrated at the bend; therefore, the wear of the elbow is more serious. The overall dynamic pressure in the flow field is stable due to the stable flow control. The flow field characteristics, without significant velocity gradients, are also consistent with the properties of high-concentration slurry transport. The maximum dynamic pressure is $9.53 \mathrm{kPa}$, which appeared at the pipeline axis. Baseline conveying pressure of the scheme with slurry concentrations of 50\%, 55\%,60\%,55\%, and 70\% were extracted, as shown in Figure 6 .

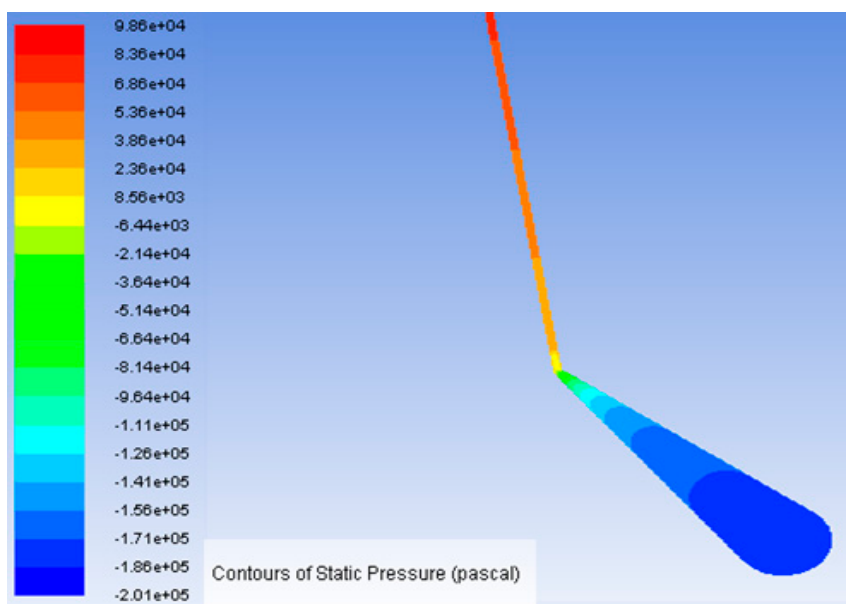

Figure 4. Contour of static pressure. 


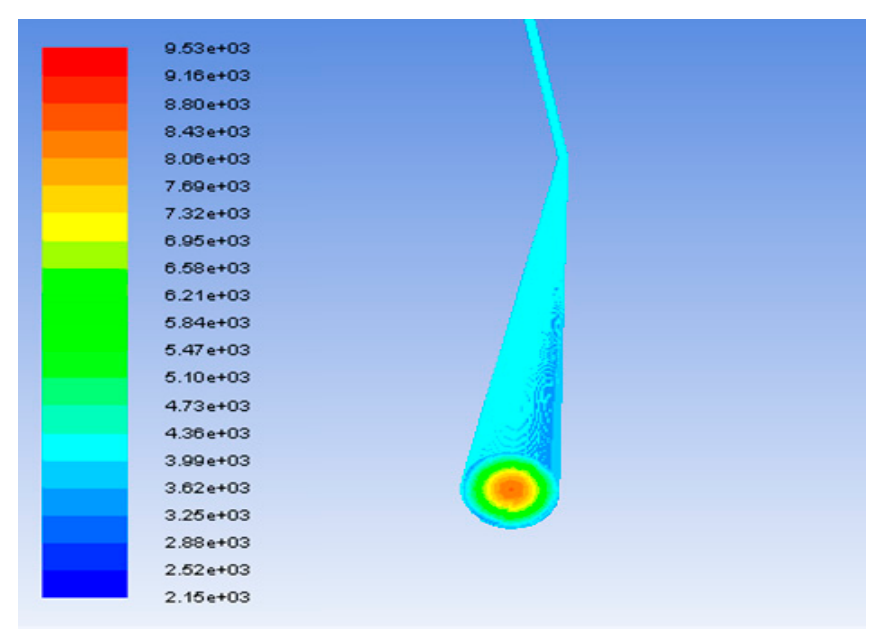

Figure 5. Contour of dynamic pressure.

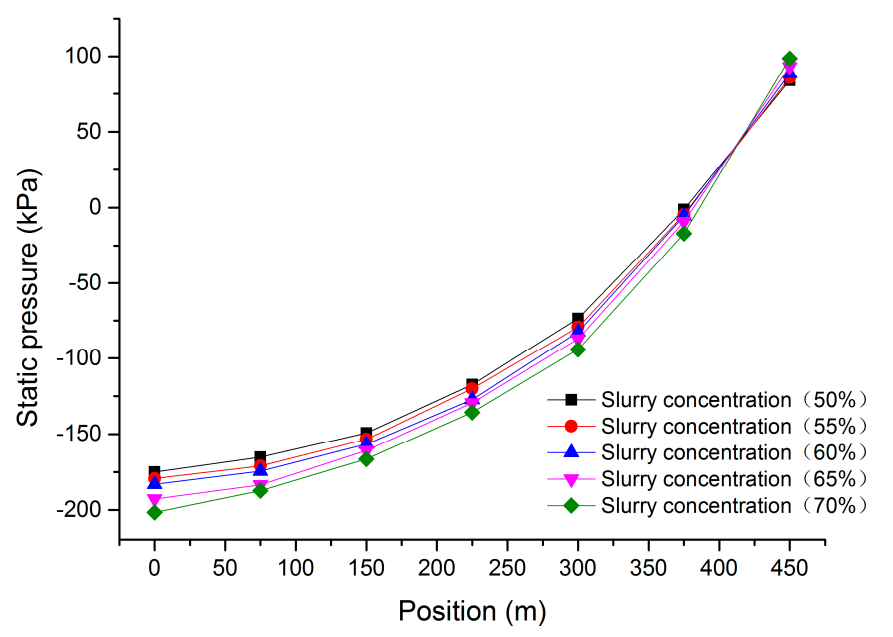

Figure 6. Conveying pressure distribution diagram of pipeline.

It is clearly observed from Figure 6 that the flow field static pressure decreases gradually from entrance to export. The lower the slurry concentration is, the lower the inlet pressure, which is contrary to the outlet pressure. Both peak values of positive pressure and negative pressure appeared in the transmission scheme with a slurry concentration of $70 \%$ and a flow rate of $70 \mathrm{~m}^{3} / \mathrm{h}$. The inlet and outlet pressures are $98.6 \mathrm{kPa}$ and $-201.5 \mathrm{kPa}$, respectively. According to the Bernoulli equation, the dynamic pressure is maintained in a stable state, thus, the static pressure difference is the pipeline resistance loss of backfilling transportation. The calculation results are shown in Table 1.

Table 1. Resistance loss of different slurry concentrations.

\begin{tabular}{cccc}
\hline Slurry Concentration (\%) & Inlet Pressure (kPa) & Outlet Pressure (kPa) & Resistance Loss (kPa) \\
\hline 70 & 98.6 & -201.5 & 300.1 \\
65 & 93.2 & -192.7 & 285.9 \\
60 & 88.5 & -183.1 & 271.6 \\
55 & 85.7 & -179.3 & 265.0 \\
50 & 83.8 & -175.1 & 258.9 \\
\hline
\end{tabular}

With different concentrations, the filling slurry shows different transport characteristics. As can be seen from the calculation of the loss of resistance in Table 1, the maximum value of the pipeline resistance loss is $300.1 \mathrm{kPa}$ (concentration $70 \%$ ) and the minimum is $258.9 \mathrm{kPa}$ ( $50 \%$ concentration). 
With the decrease of slurry concentration, the absolute value of pipeline transportation pressure became smaller, and the resistance loss decreased. The difference of inlet pressure between the solutions is low (about $4 \mathrm{kPa}$ ), but the difference in the outlet pressure is increased (up to nearly $10 \mathrm{kPa}$ ). This indicates that the increase of the slurry concentration increases the viscous resistance between the pipe wall and particle flow at the same flow rate. When the slurry concentration is less than $60 \%$, the resistance loss is reduced to below $10 \mathrm{kPa}$. The main reason for this is that, with continuous dilution, the slurry fluidity is improved. However, with the decrease of the tailing sand content, the decreasing trend of the fluid density slows and the magnitude of the improvement decreases. A comparison between the two schemes shows that the decrease of the slurry concentration in the steady flow field can help the fluidity, but, when the slurry concentration is lower than $60 \%$, the effect is not obvious.

Since the particle collision angle function proposed by Huser and Kvernvold [22] is used by the CFD model, and a number of erosion empirical models, we applied this model for erosion calculations.

$$
R_{\text {erosion }}=\sum_{n=1}^{N} \frac{m_{p} G\left(d_{p}\right) f(\theta) u_{p}^{b(v)}}{A_{\text {face }}}
$$

where $R_{\text {erosion }}$ is the wall erosion rate, $\mathrm{kg} / \mathrm{m}^{2} \cdot \mathrm{s} ; N$ is the number of particle collisions; $m_{p}$ is the mass flow rate of particles $\mathrm{kg} / \mathrm{s} ; G\left(d_{p}\right)$ is the particle size function; $b(v)$ is the relative velocity function; $A_{\text {face }}$ is the area of the unit, $\mathrm{m}^{2}$; and $\theta$ is the wall collision angle, wherein:

$$
f(\theta)=2.69 \theta+1.61 \theta^{2}-8.84 \theta^{3}+7.33 \theta^{4}-1.85 \theta^{5}
$$

The results of the wall erosion rate under different concentrations were extracted, as shown in Figure 7.

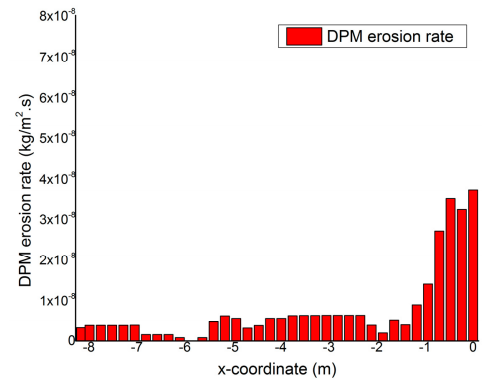

Concentration $(50 \%)$

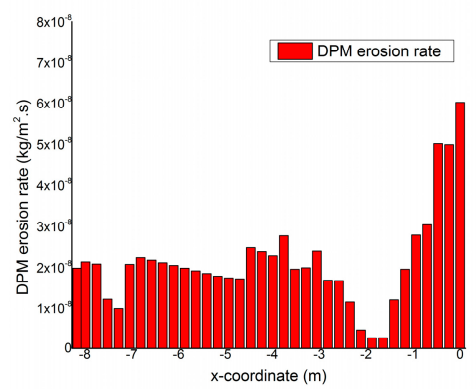

Concentration $(65 \%)$
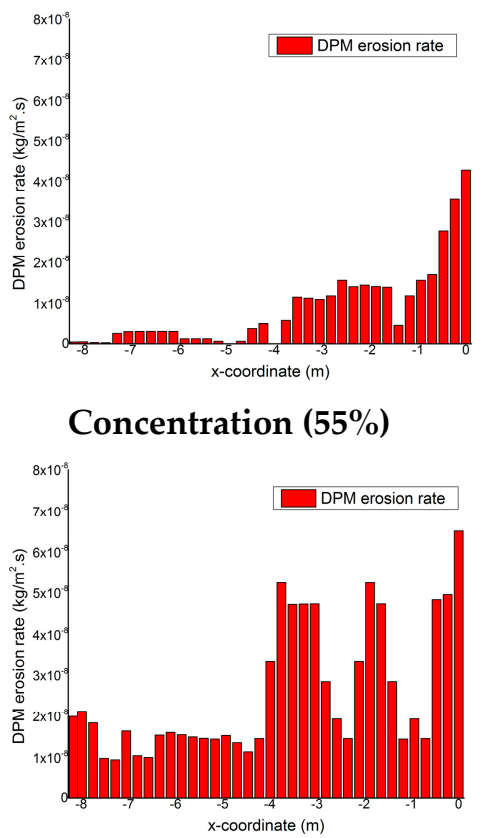

Concentration (70\%)

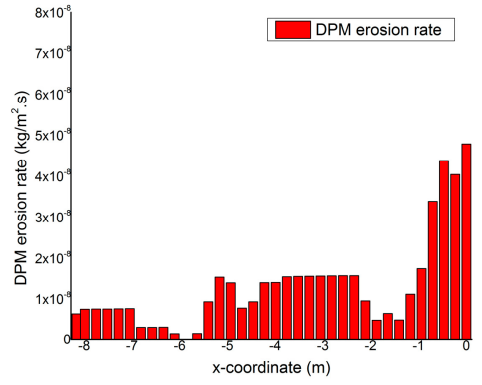

Concentration $(60 \%)$

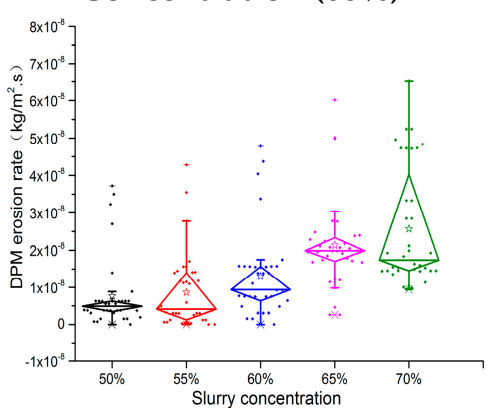

Erosion contrast chart

Figure 7. Erosion monitoring results of different slurry concentrations.

The erosion rate is calculated by counting the cumulative damage of each particle to the wall. It can be seen from the erosion diagram of the different concentration schemes that the main scope of erosion influence is in the range of about $8 \mathrm{~m}$ from the elbow; the closer to the elbow, the more obvious the increase in erosion rate. The maximum erosion rate appears in the origin, the minimum value is 
$3.72 \times 10^{-8} \mathrm{~kg} / \mathrm{m}^{2} \cdot \mathrm{s}$ (concentration $50 \%$ ), the maximum value is $6.51 \times 10^{-8} \mathrm{~kg} / \mathrm{m}^{2} \cdot \mathrm{s}$ (concentration $70 \%$ ). From the comparison of the maximum erosion rate and the influence range of different schemes, it can be seen that, when the slurry concentration is less than $60 \%$, the erosion rate and influence range increase slowly, and the average erosion rate is below $1.00 \times 10^{-8} \mathrm{~kg} / \mathrm{m}^{2} \cdot \mathrm{s}$. When the concentration is higher than $60 \%$, the erosion rate increases significantly, and the average erosion rate exceeds $1.50 \times 10^{-8} \mathrm{~kg} / \mathrm{m}^{2} \cdot \mathrm{s}$, the maximum erosion rate exceeds $6 \times 10^{-8} \mathrm{~kg} / \mathrm{m}^{2} \cdot \mathrm{s}$. In the scheme of a slurry concentration of $70 \%$, the erosion rate obviously fluctuated, and the grain flow shows an unstable state, indicating that the erosion area is no longer concentrated in the pipeline bus, and obvious diffusion occurs. There is a significant turbulence in the elbow, which presents a risk of slurry leakage.

The erosion contrast chart was developed in order to show the erosion range in different scenarios. It can be seen that, with the increase of slurry concentration, the median value of the erosion rate experiences a near-linear growth, indicating that, with the increase of concentration, the erosion of particles continue to accumulate. With the removal of outliers, the minimum erosion rate of schemes with slurry concentrations of $65 \%$ and $70 \%$ exceed $1.00 \times 10^{-8} \mathrm{~kg} / \mathrm{m}^{2} \cdot \mathrm{s}$, significantly exceeding other schemes, which is not conducive to transport stability. When the concentration does not exceed $60 \%$, the erosion box diagrams are stable at a low level. The erosion of the filling pipeline is a long-term effect, and the erosion of the solid phase on the pipeline will continue until the bottom of the pipe is damaged. It can be seen from the comparison that, under the conditions of gravity transport, the control of slurry concentrations (not more than $60 \%$ ) is helpful to maintain the stability of the flow field and lower erosion damage.

Different from the pressure and velocity distributions, the flow of backfilling particles are heterogeneous, although initial velocity boundary conditions of the particle phase were fixed for a uniform flow. This is mainly caused by the interphase coupling effect, collision, and friction with the pipe shell in the flow field. With slurry particle size parameters set, the discrete phase particle movement of schemes with different slurry concentrations was simulated. Results are shown in Figure 8.

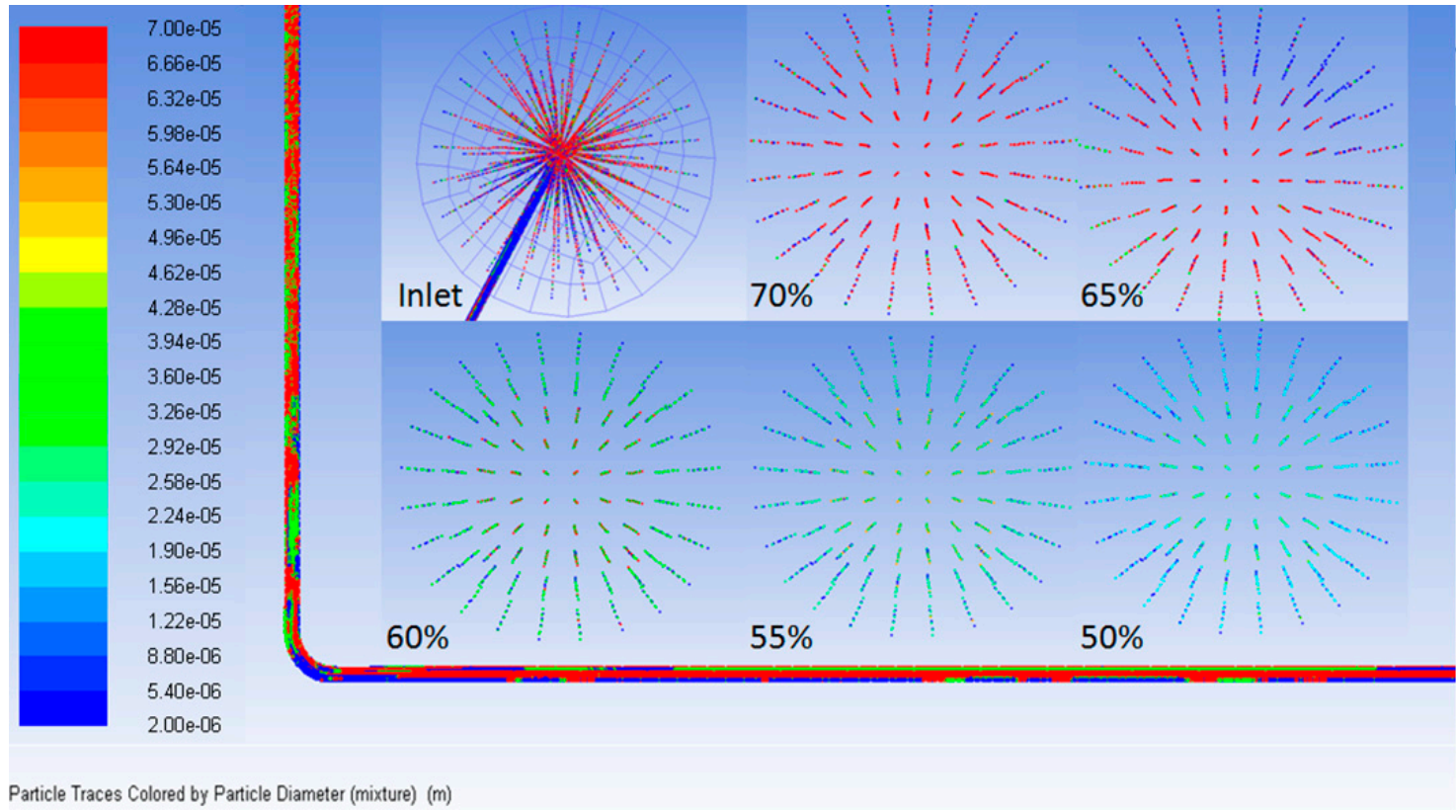

Figure 8. Distribution of discrete phase particle.

Figure 8 shows the movement and distribution of dispersed phase particles in the pipeline (cross-sectional and longitudinal). Measurements of 0.002 0.07 mm (content more than 90\%) were set up as the particle size constraints for demonstration of accurate analysis results. As shown, 
particle motion is relatively stable in the vertical pipe section, in addition to a certain degree of separation at the end, mainly due to the viscous forces of the wall. Particle size distribution is obviously changed at the elbow, showing a non-linear mixed flow state. At this stage, interphase interactions and erosion effects of the tube wall are obviously increased. The ultimate appearance of flow field characteristics in the horizontal branch is an unsteady particle mixing flow. Particle flow characteristics of the flow field were accurately simulated using the dense phase particle model.

The distribution of dispersed phase particles $8 \sim 10 \mathrm{~m}$ out the bend is shown on the right side of Figure 8 (corresponding to the results in Table 2). This region is a high turbulence area for pipeline transportation. It can be seen that the coarse particles concentrate at the center of the pipe; the closer to the wall, the more obvious the fine particle distributions are, due to the smaller viscosities. The particle size distribution at different slurry concentrations is shown in Table 2. It was found that the particle diameter range of the $65 \%$ scheme is $0.007-0.17 \mathrm{~mm}$, and in the concentration range of the $70 \%$ scheme, it is $0.011-0.25 \mathrm{~mm}$. Under the conditions of high concentration transportation, the coarse particle distribution is obvious and the weighted average diameter is more than $0.045 \mathrm{~mm}$. With the decrease in concentration, the trace amounts of coarse particles decrease, as with the content of coarse particles. The particle size range of the $50 \%$ scheme is $0.002-0.049 \mathrm{~mm}$, with coarse particle content decreases.

Table 2. Particle size distribution after erosion.

\begin{tabular}{ccc}
\hline Slurry Concentration (\%) & Particle Size Range (mm) & Weighted Average Value (mm) \\
\hline 70 & $0.011-0.25$ & 0.059 \\
65 & $0.007-0.17$ & 0.045 \\
60 & $0.002-0.11$ & 0.027 \\
55 & $0.002-0.066$ & 0.021 \\
50 & $0.002-0.049$ & 0.018 \\
\hline
\end{tabular}

Different slurry concentration schemes showed different grain size characteristics in the post-eroded zone, and the reasons can be summarized as follows:

In schemes with $65 \%$ and $70 \%$ concentrations, the tailing erosion is obvious and local turbulence is formed near the elbow. The original particle size structures of the particles re broken and the distribution is obviously uneven, resulting in a concentrated distribution of coarse particles. Siltation and plugging may be caused by the long-term erosion effect of the particle flow. In the 55\% and $50 \%$ schemes, although the fluidity is good, there is obvious shear thinning in the post-eroded area due to the low content of particles and the poor viscosity, leading to particle size separation, which is not conducive to backfill integrity.

These two conditions are not conducive to the continuity of the filling operation due to the uniform content of the total particles during transport. By comparing the particle size characteristics of the post-eroded zone, it can be seen that the weighted average particle diameter values increase with concentration, and the average particle diameter of the $60 \%$ slurry concentration is $0.027 \mathrm{~mm}$, the closest to the particle size curve fitting characterization of $0.026 \mathrm{~mm}$. After erosion, the flow field gradually returns to a laminar flow state. Particle flow mixing and separation are reduced. The scheme with a $60 \%$ concentration keeps the homogeneity of the slurry and the integrity of the flow field, which are the most favorable schemes.

By summarizing the analysis results of resistance loss, erosion rate, and particle size distributions, the scheme with a slurry concentration $60 \%$ satisfies the demand of high concentration, ultrafine backfilling transportation, with little resistance loss, erosion rate, and good particle uniformity. The scheme can guarantee the transmission stability and cemented backfill integrity.

\subsection{Slurry Flow Analyses}

Backfilling pipeline flow optimization was conducted based on the results of the concentration analysis. In the first stage of simulation, the initial slurry concentration was set to $60 \%$, slurry transportation 
simulation analyses of different slurry flows $\left(50,55,60,65\right.$, and $\left.70 \mathrm{~m}^{3} / \mathrm{h}\right)$ were conducted under these conditions. Pressure calculation results are shown in Table 3.

Table 3. Resistance loss of different slurry flows.

\begin{tabular}{cccc}
\hline Volume Flow $\mathbf{~}^{\mathbf{3}} \cdot \mathbf{h}^{-\mathbf{1})}$ & Inlet Pressure (kPa) & Outlet Pressure (kPa) & Resistance Loss $\mathbf{( k P a )}$ \\
\hline 70 & 88.5 & -183.1 & 271.6 \\
65 & 79.6 & -170.4 & 250.0 \\
60 & 70.9 & -158.3 & 229.2 \\
55 & 61.3 & -146.2 & 207.5 \\
50 & 53.4 & -125.9 & 179.3 \\
\hline
\end{tabular}

When the flow rate is not the same, filling transportation shows different resistance characteristics. From the results of the resistance loss calculation in Table 2, it can be seen that the maximum value of pipeline resistance loss is $271.6 \mathrm{kPa}$ (flow $70 \mathrm{~m}^{3} / \mathrm{h}$ ), the minimum value is $179.3 \mathrm{kPa}\left(\mathrm{flow} 50 \mathrm{~m}^{3} / \mathrm{h}\right.$ ). With the decrease of the conveying flow, the absolute value of the pipe conveying pressure becomes smaller, and the resistance loss gradually decreases. The loss difference between the two schemes is about $20 \mathrm{kPa}$, indicating that the resistance loss of the two-phase flow will increase with an increase in the slurry flow rate under the same concentration conditions. According to Figure 8, when the slurry flow continues to decrease, the pipe resistance loss showed a near-linear trend. The results of Figure 8 show that the maximum value of the shear stress is $229.7 \mathrm{~Pa}$ with a flow rate of $70 \mathrm{~m}^{3} / \mathrm{h}$ and a minimum value $148.4 \mathrm{~Pa}$ with flow rate of $50 \mathrm{~m}^{3} / \mathrm{h}$. With the increase in the conveying flow, the shear stress of the wall is obviously increased.

As can be seen from the results shown in Figure 9, at a flow rate of $50 \sim 70 \mathrm{~m}^{3} / \mathrm{h}$, the pipeline resistance loss and wall shear stress exhibit a linear growth trend. The main reason for this is that, in the solid and liquid two-phase full flow state, the concentration and flow are relatively stable; when the flow changes, the frequency of the particle phase experiences flow field changes. As the flow rate increases, the wall resistance, the interphase drag force, and the internal collision of the dispersed phase will increase, leading to increased energy consumption and resistance loss. At the same time, the collisions and friction between the particle flow and the wall increase, which leads to an increase of wall shear stress. This result shows that, unlike the concentration change, the impact of the change of the conveying flow on the resistance and wear of a pipeline is direct. If the flow velocity is too large, the transportation consumption and the wall wear will increase. Long-term work is liable to cause slurry and leakage. Through comparison of the schemes, it is shown that, under the premise of satisfying the conveying capacity of filling slurry, the conveying flow should be minimized in order to reduce the resistance loss of pipeline transportation, thus reducing the energy consumption and pipe wear.

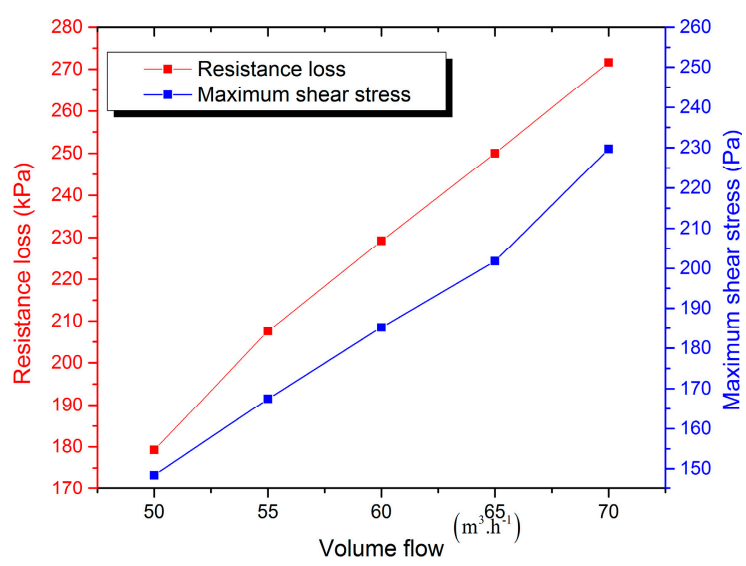

Figure 9. Influence of flow rate on resistance and shear stress. 
Slurry flow, not only related to the size of the conveyor resistance loss, also affects pipeline stress and the distribution of the solid phase. The elbow branch was set as the research domain for analyses on shear stress and discrete phase mass fraction of schemes with different volume flows, as shown in Figure 10.

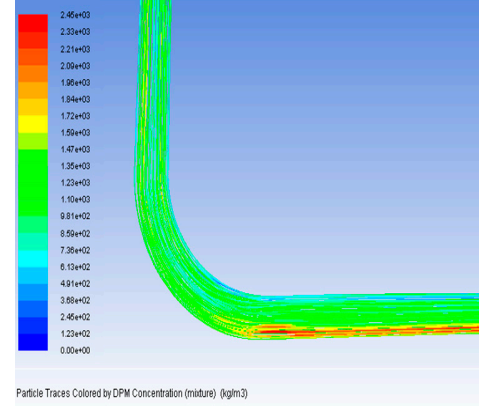

Slurry flow $\left(50 \mathrm{~m}^{3} \cdot \mathrm{h}^{-1}\right)$

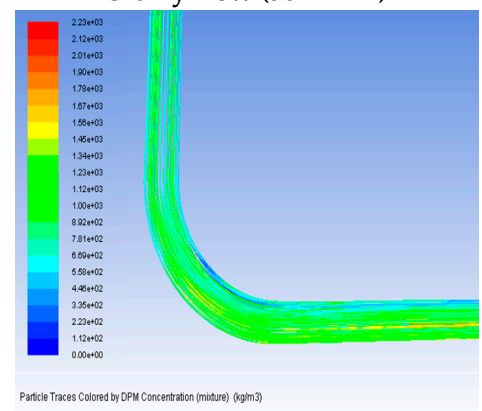

Slurry flow $\left(65 \mathrm{~m}^{3} \cdot \mathrm{h}^{-1}\right)$

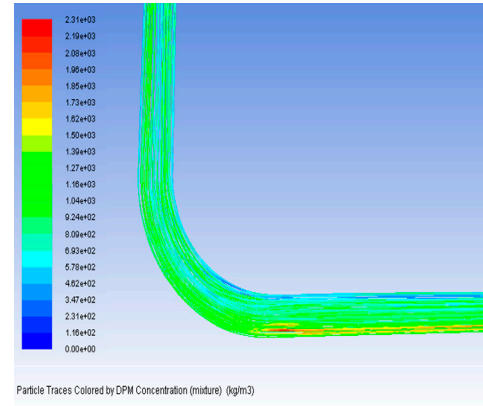

Slurry flow $\left(55 \mathrm{~m}^{3} \cdot \mathrm{h}^{-1}\right)$

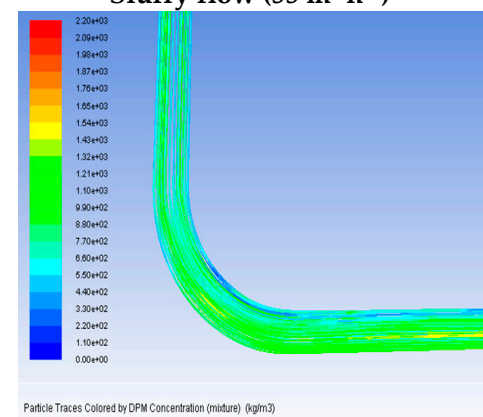

Slurry flow $\left(70 \mathrm{~m}^{3} \cdot \mathrm{h}^{-1}\right)$

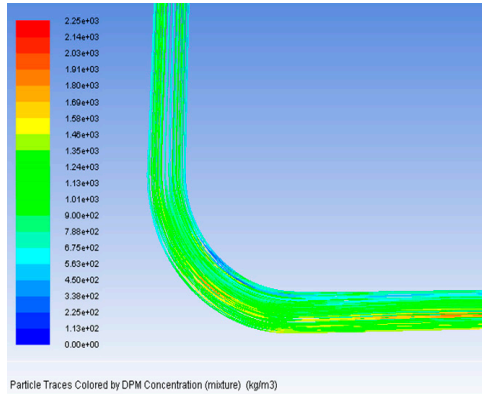

Slurry flow $\left(60 \mathrm{~m}^{3} \cdot \mathrm{h}^{-1}\right)$

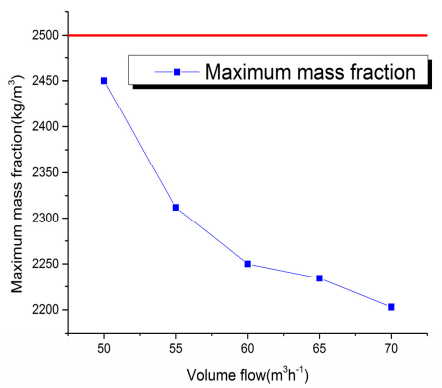

Mass fraction of different slurry flows

Figure 10. Distribution of discrete phase mass fraction.

Figure 10 shows the mass distribution of the discrete phase with different flow rates. During the filling process, the distribution of the discrete phase is relatively uniform in the front part of the elbow. After the elbow, due to erosion and sedimentation, the dispersed phase particles concentrated at the bottom of the pipeline. During this period, particle flow has undergone the biggest erosion stage during the transportation process. In the slurry, some tailing particles settled due to a depletion of kinetic energy. As can be seen from the nephogram in Figure 10, the mass fraction of the upper part of the pipeline is significantly lower than the bottom, so that the bottom of the pipeline at this time experienced particle aggregation. When disturbed by turbulence in the flow field, tailings particles restarted movement, but, if the flow is insufficient, siltation occurs in tailing particles that cannot be transported. The curve shows the maximum mass fraction at the elbow at different flows. When the flow rate decreases, the mass fraction of the dispersed phase increases. When the flow rate is less than $55 \mathrm{~m}^{3} / \mathrm{h}$, the mass fraction obviously increases. When the flow rate reaches $50 \mathrm{~m}^{3} / \mathrm{h}$, the maximum mass fraction reaches $2450 \mathrm{~kg} / \mathrm{m}^{3}$, and the particle aggregation range is also larger than in other schemes. The red line shows the solid phase density $\left(2500 \mathrm{~kg} / \mathrm{m}^{3}\right)$, indicating that, in this scheme, the filling slurry is likely to form dehydration deposition.

As the filling slurry is a two-phase mixed flow with high solid content, the high content of the tailings may cause sedimentation of the pipeline during transportation. As a key part of pipeline transportation, the probability of silt deposition is highest at the bend, and it is also a problem for areas of high obstruction, which directly affects the operation of the filling system. Moreover, accumulative siltation will greatly reduce the service life of a pipeline. The problem of tailing sedimentation depends on the velocity of pipeline transportation. Excessive flow velocity will cause erosion damage and resistance loss of a pipeline, and can even cause pipeline leakage. A flow rate that is too low will cause the tailings to be deposited in the transportation process, not only causing pipe blockage, but can 
also reduce the quality of backfills. For the purpose of reducing energy consumption and pipe wear, a lower flow rate should be selected when the filling demand has been met. From analyses of the mass fraction of the dispersed phase, it can be concluded that a flow rate of $50 \mathrm{~m}^{3} / \mathrm{h}$ leads to obvious concentrations of particle phase mass distribution. With an increase in conveying distance, the slurry can be dehydrated. When the flow rate reaches $55 \mathrm{~m}^{3} / \mathrm{h}$, the concentration trend of the discrete phase is not obvious, and the maximum mass fraction decreased significantly. Therefore, in order to reduce resistance loss, while controlling the deposition of the discrete phase, and to ensure filling efficiency, the transport scheme with a flow rate of $55 \mathrm{~m}^{3} / \mathrm{h}$ was selected for reasonable delivery. The requirements of the backfilling system capacity at the Mercury Cave gold mine is $300 \mathrm{~m}^{3} / \mathrm{d}$, setting an effective work time of six hours will meet the requirements.

The numerical simulation work established the pipeline flow field model using the CFD-DDPM (computational fluid dynamics-dense discrete phase model) method, with interface drag forces and particle size distribution characteristics of the imported transmission. Accuracy of calculation results was guaranteed by function fitting and the UDF method. Different from the optimization method, by only reducing the concentration and flow rate [21], a variety of factors were considered in the analysis. Combining the conclusions, mentioned above, transportation parameters with a slurry concentration of $60 \%$, a volume flow $55 \mathrm{~m}^{3} / \mathrm{h}$ was selected as the optimal transportation scheme.

\section{Experimental Verification}

Appropriate backfilling transportation parameters were determined through analysis of dense-phase mixed flows and the discrete phase characteristics using the DDPM method. Laboratory tests and field industrial tests were conducted in order to verify the reliability of the numerical simulation results. Figure 11 shows the internal relationship between the simulation analyses and the experimental method. The resistance loss, wear of the pipeline, degree of siltation, and integrity of filling are taken as the verification indeces to reflect the correspondence between the DDPM method and the experiment.

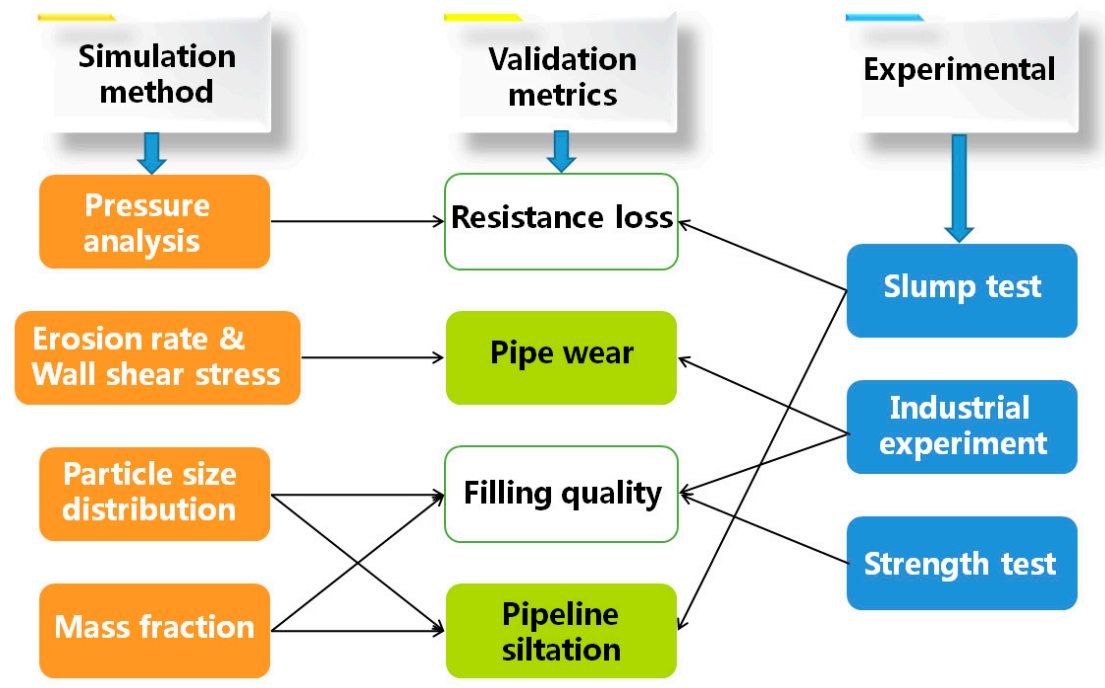

Figure 11. Internal relations of research methods.

\subsection{Slurry Slump Rest}

Slurry liquidity is an important feature of backfilling transportation. A slump test is a testing method used to determine mixture viscosity, deformation properties, and the rheology resistance of backfilling slurry. The higher the slump, the better the slurry liquidity is. Slump test results are shown in Table 4 and Figure 12. 
Table 4. Slump of different slurry concentration.

\begin{tabular}{cccccc}
\hline Slurry Concentration (\%) & $\mathbf{5 0}$ & $\mathbf{5 5}$ & $\mathbf{6 0}$ & $\mathbf{6 5}$ & $\mathbf{7 0}$ \\
\hline Slump/cm & - & 27.6 & 22.1 & 16.8 & 10.1 \\
\hline
\end{tabular}
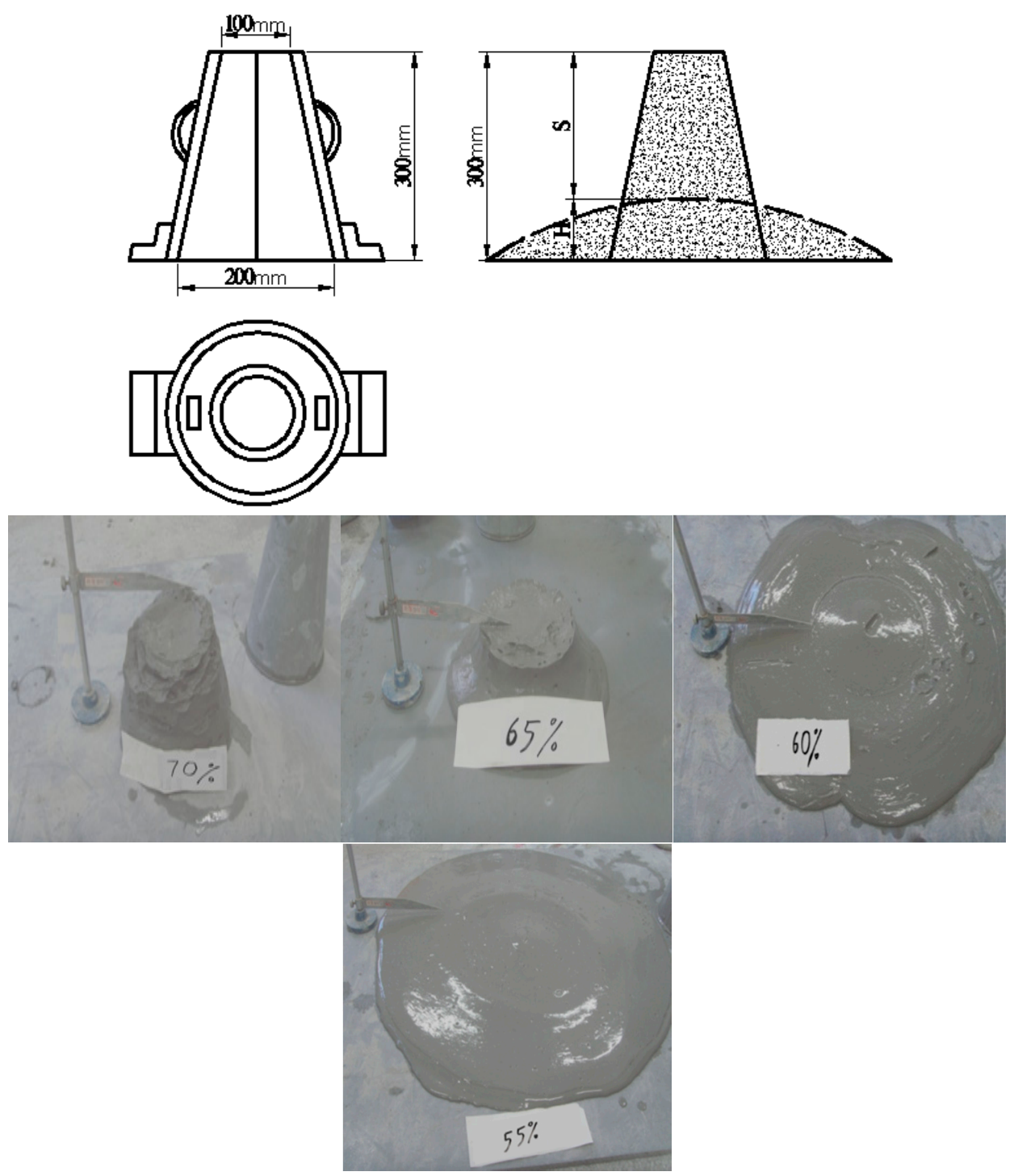

Figure 12. Backfill slurry slump test.

From the slurry slump test of different concentrations, we can determine that slurry fluidity improves when the slurry concentration is stepped down. The slump is $27.6 \mathrm{~cm}$ with a slurry concentration $55 \%$, the water retention performance of the slurry is low, and the sample shows a small amount of segregation and dehydration; thus, the apparent concentration indicates poor plasticity. Slump cannot be measured when the slurry concentration is $50 \%$, which does not match backfilling transportation standards. The plasticity of samples is enhanced when the slurry concentration increases, showing a degree of concreteness. The slump of the scheme with a slurry concentration of $60 \%$ is $22.1 \mathrm{~cm}$, accompanying by high concentrations, liquidity, and good plasticity. This is the best choice for gravity backfilling, and verifies the correctness of the simulation results. 


\subsection{Backfill Strength Test}

A backfill strength test can be used to determine the consolidation properties and strength index of samples with different slurry concentrations and ratios, in order to estimate whether backfills meet the strength and technical requirements of mining engineering. Portland cement (325\#) and unclassified backfill were combined to produce specimens. Cube specimens $(7 \mathrm{~cm}$ length) were designed with cemented-tailing ratios of 1:4, 1:6, and 1:8, and slurry concentrations of $55 \%, 60 \%$, and $65 \%$; a total of nine groups were used. The strength after being cured for 7 days, 14 days, and 28 days were tested, as shown in Figure 13.

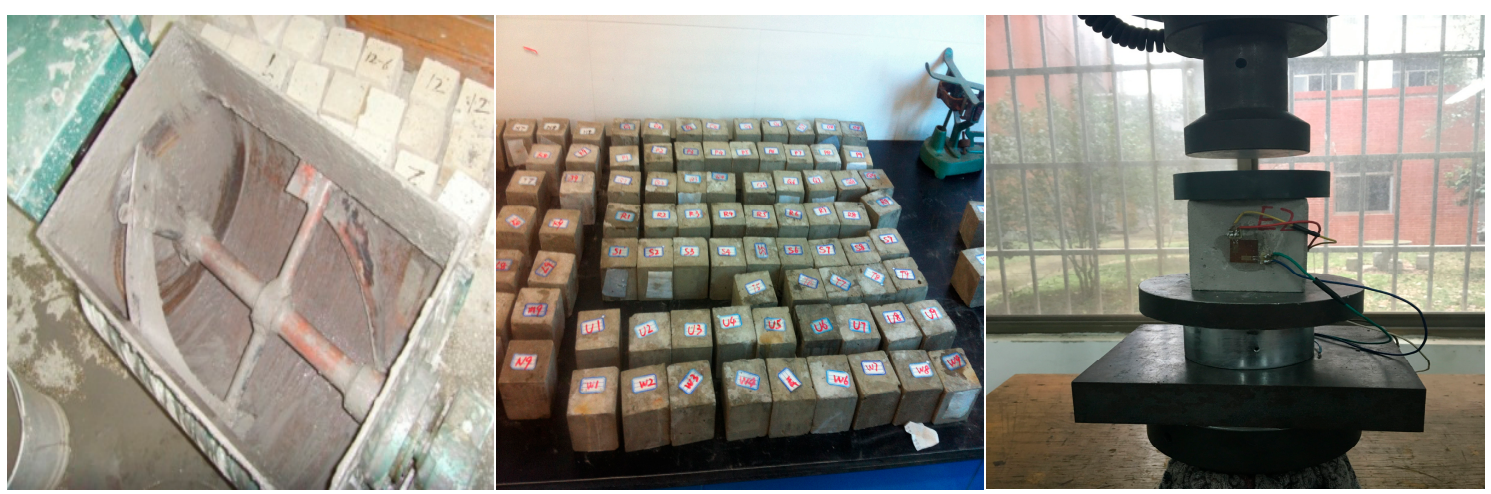

Figure 13. Backfill strength test.

The experimental data of backfills in different stages were summarized and are shown in Figure 14. The backfill strength test, combining schemes of different ratios and slurry concentration tests, effectively predict the long-term strength of backfills. An increase in concentration and the ratio can improve the strength of backfills. When the cemented-tailing ratio being low, there is little difference between the strength of filling bodies with different concentrations. When the cemented-tailing ratio is higher, the results are quite different. As can be seen from the test results, the seven-day strength of all specimens with a slurry concentration of $55 \%$ is less than $0.5 \mathrm{MPa}$, which cannot meet technical requirements. After being cured for 28 days, the lowest strength value of the backfill specimens with a slurry concentration of $60 \%$ is $2.16 \mathrm{MPa}$ (cemented-tailing ratio of $1: 8$ ). The strength of other high-ratio specimens is more than $2.50 \mathrm{MPa}$, which matches the demand of industry standard capabilities. Based on the characteristics of backfill strength, when a gravity conveyor is implemented, industry strength requirements can be satisfied by adjusting the cemented-tailing ratio. The results also verify the feasibility of the numerical simulation results.
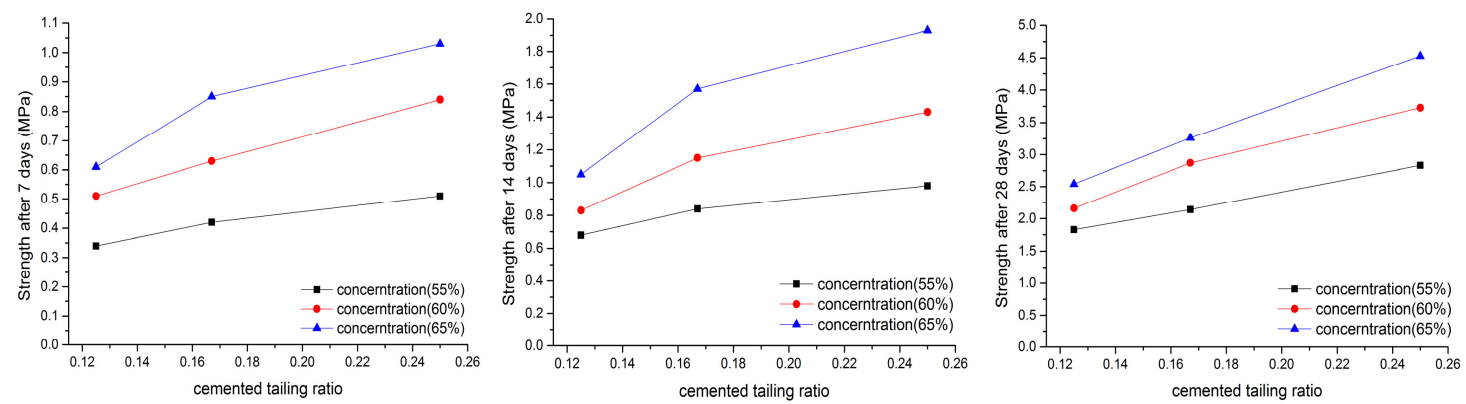

Figure 14. Results of backfill strength test.

\subsection{Industrial Test}

In order to determine reasonable pipeline flow and backfilling results, and to validate the results of the experiments and simulations, a field backfilling transportation industrial test was conducted. 
A mine filling station was in the process of improvments, and part of the process needs to be controlled artificially. The filling slurry preparation process is as follows: First of all, backfilling slurry was made using high-pressure gas in a vertical tailing bin. The slurry flowed into pipeline at the bottom of the tailing bin, and the volume of the slurry flow was determined by a flowmeter. After, according to the slurry flow rate, slurry concentration (artificial setting) and cemented-tailing ratio, water, and a material feeder were set up using the electric control valve. Finally, the slurry was mixed in a double shaft mixer and transported into the test area. The cut lane and mined-out area in the 1240-m stage section were selected as the test area; an electromagnetic flowmeter was used to monitor the volume flow of the entire slurry transportation process. Two slurry concentrations (55\% and 60\%) were tested in the experiment, as shown in Figure 15.

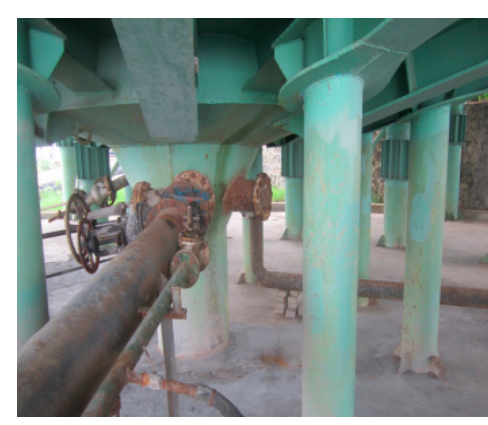

(a)

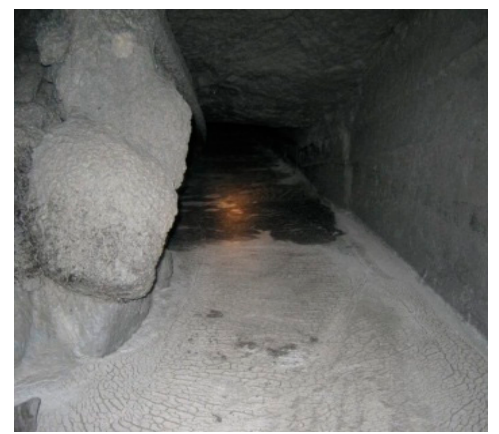

(d)

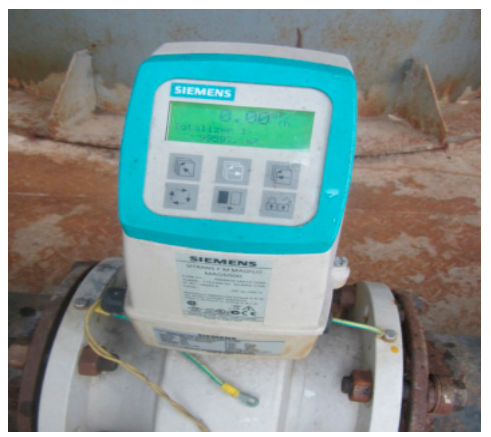

(b)

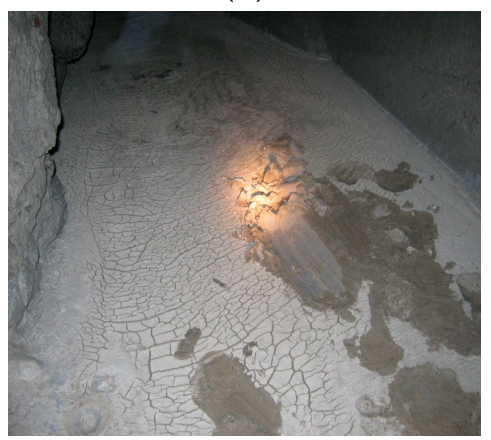

(e)

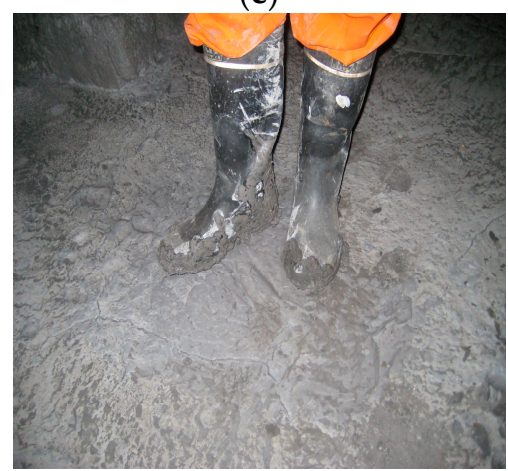

(g)

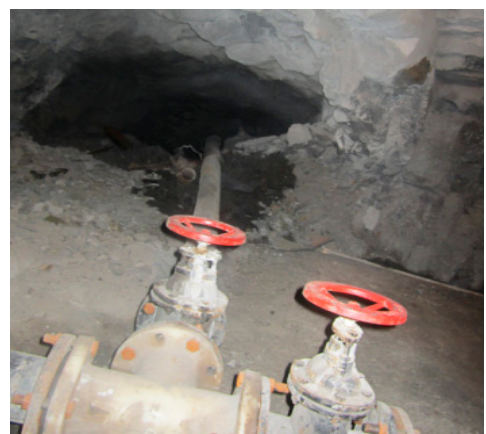

(c)

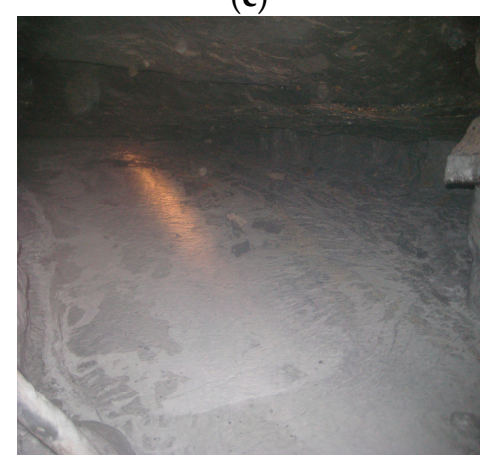

$(\mathbf{f})$

Figure 15. Backfilling transportation industrial test. (a) Thickener; (b) Electromagnetic flowmeter; (c) Pipeline transportation; (d) $24 \mathrm{~h}$ after filled (concentration 55\%); (e) $72 \mathrm{~h}$ after filled (concentration $55 \%$ ); (f) $24 \mathrm{~h}$ after filled (concentration 60\%); (g) $72 \mathrm{~h}$ after filled (concentration $60 \%$ ).

Flow rate analysis results were acquired via test area monitoring. In the scheme with a slurry concentration of $60 \%$, the volume flow was set from 50 to $60 \mathrm{~m}^{3} / \mathrm{h}$. Observed results show that leakage problems appeared at the filling retaining wall and pipe when the flow rate neared $60 \mathrm{~m}^{3} / \mathrm{h}$. 
When the flow rate was set to $55 \mathrm{~m}^{3} / \mathrm{h}$, the system ran normally. By comparing the two schemes, obvious differences can be seen, as shown in Figure 12. In the scheme with a slurry concentration of $55 \%$, water seepage appeared on the backfill surface after being filled for $24 \mathrm{~h}$, and cracking occurred in most areas. After $72 \mathrm{~h}$, the backfill surface was still not consolidated for passage. Roof-contacted filling cannot be executed, thus, cemented rock-tailings fill is required to close the area. In the scheme with a slurry concentration of $55 \%$, no obvious water seepage appeared on the backfill surface after being filled for $24 \mathrm{~h}$. After $72 \mathrm{~h}$, the backfill harshness was good for personnel access. Industrial tests prove that the transportation parameter of a slurry concentration of $60 \%$ and a volume flow of $55 \mathrm{~m}^{3} / \mathrm{h}$ is efficient. The results of the numerical simulations and the laboratory tests were validated.

\section{Summary and Conclusions}

The flow field model of a CFD-DDPM pipeline was established, and the problems of interphase transport and high concentrations in backfilling were considered. According to the characteristics of the particle size distributions of ultrafine tailings, the morphological diameter function is defined as the initial condition, and the complex flow and solid discrete phase flow field are calculated and tracked, in combination with the Euler-Lagrangian method. The interphase drag force model was improved by the secondary development of a compiled language, which improves the recognition degree of fluidized calculations. Different from the study of volume flow and concentrations in conventional two-phase flow simulations, with the loss of resistance, pipe wear, siltation degree, and filling integrity as the analysis indices, multiple flow field factors were selected for analyses.

The erosion resistance, erosion rate, and particle size distributions were analyzed and compared for slurry concentration schemes $(50 \%, 55 \%, 60 \%, 65 \%$, and $70 \%)$. It can be concluded that, with continuous dilution, the fluidity of slurry is improved and the resistance loss is reduced. However, with a decrease of tailing sand content, the decreasing trend of fluid density is slowed and the magnitude of resistance control decreases. The results show that the erosion area is about $8 \mathrm{~m}$ away from the elbow, and when closer to the elbow, the erosion rate increases. When the slurry concentration is higher than $60 \%$, the erosion rate increased significantly, mean value exceeded $1.50 \times 10^{-8} \mathrm{~kg} / \mathrm{m}^{2} \cdot \mathrm{s}$, maximum erosion rate exceeded $6 \times 10^{-8} \mathrm{~kg} / \mathrm{m}^{2} \cdot \mathrm{s}$, the influence range was obviously increased, and long-term effects could damage the pipeline system. The particle size variety in the process of transportation was analyzed by distribution of the post-eroded zone. The original grain size structure was broken due to the turbulence effect near the elbow. The concentration of coarse particles in high-concentration slurry (65\% and 70\%) may cause blockages. Low-concentration slurry $(50 \%, 55 \%)$ causes shear thinning due to poor viscosity, and may reduce the filling quality. The average particle size of the slurry with a concentration of $60 \%$ was $0.027 \mathrm{~mm}$, which is closest to the initial particle size. The scheme can guarantee transportation stability and backfill integrity.

By comparing resistance losses, wall shear stress, and mass fraction of the slurry flow schemes $\left(50,55,60,65\right.$ and $\left.70 \mathrm{~m}^{3} / \mathrm{h}\right)$, it can be concluded that, as the transport flow increases, the resistance loss and shear stress tends to increase linearly, and excessive flow can cause pipeline damage and leakage. Extremely low flow rates should be selected when filling and conveying requirements are met. The resistance loss is $207.5 \mathrm{kpa}$ and the maximum shear stress is $167.5 \mathrm{~Pa}$ for a flow rate of $55 \mathrm{~m}^{3} / \mathrm{h}$, which is a relatively low level. In the control of siltation, the maximum mass fraction of the dispersed phase is $2312 \mathrm{~kg} / \mathrm{m}^{3}$ with a flow rate of $55 \mathrm{~m}^{3} / \mathrm{h}$, and the concentration range of the discrete phase is small. From the perspective of mine filling demands, a flow rate of $55 \mathrm{~m}^{3} / \mathrm{h}$ meets the needs of gravity transport.

In order to verify the proposed method, slump, filling strength, and the industrial transportation were experimentally verified. The results show that, with the increase of slurry concentration, the plasticity of samples increase; however, when the concentration is high, it shows a certain degree of consolidation, which can not meet the requirements of gravity transport. Lower concentrations of slurry also showed thinning and seepage. After being cured for 28 days, the lowest strength value of backfill specimens with a slurry concentration of $60 \%$ was $2.16 \mathrm{MPa}$ (cemented-tailing ratio of $1: 8$ ). In terms 
of strength, the slurry concentration also reached industrial requirements. Industrial experiments showed that gravity flow should be controlled within the scope of not more than $55 \mathrm{~m}^{3} / \mathrm{h}$ and backfill with a $60 \%$ concentration met the needs of mining technology and management of mining goaf areas. Therefore, the following conclusions can be drawn:

(1) In the process of backfilling transportation, pipeline resistance loss and abrasion can be controlled by reducing the flow rate and slurry concentration. Discrete phase analysis results show that reducing transportation parameters may lead to slurry dehydration and low backfill strength. Therefore, transportation parameters need to be controlled within an effective range, in order to realize efficient backfilling.

(2) By application of the CFD-DDPM solid-liquid phase flow model, analyses on multifactor (pressure, particle size distribution, erosion and mass fraction) in two phase mixture flow was conducted. Optimal transportation parameters with a slurry concentration of $60 \%$ and volume flow of $55 \mathrm{~m}^{3} / \mathrm{h}$ were obtained using simulations and experiments. This method can be used by other mining enterprises.

(3) This work is more of a numerical method development, laboratory experiments and industrial experiments were used to verify and calibrate the numerical model. Therefore, a large number of other experiments with different standards have not been carried out. However, in the case of gravity transport, the results and achievements can be accurately used in the design of filling pipeline transport with particle flow characteristics. This method can reduce the dependence on large-scale loop experiments and industrial verification, and also has reference values for oil and gas transportation and water transportation. On the basis of the further development of the software language, the combination of DDPM and experiments is feasible. In order to enhance the fluidity and the filling strength of mining enterprises, the methods of paste filling and coarse aggregate transportation need to be further improved using DDPM methods. Further research is expected to be realized to have more possibilities in backfilling transportation.

Acknowledgments: The authors would like to acknowledge that the work was supported by the National Natural Science Foundation of China (grant No. 51274253 and No. 51474252).

Author Contributions: For the contribution of the author to this article: Ke-ping Zhou, Rugao Gao and Feng Gao conceived and designed the experiments; Ke-ping Zhou and Rugao Gao performed the simulation and the experiments; Rugao Gao and Feng Gao analyzed the data; Rugao Gao wrote the paper.

Conflicts of Interest: The authors declare no conflict of interest.

\section{Nomenclature}

$\mathrm{G}=$ particle cumulative percentage
$\mathrm{d}=$ particle size
$\mathrm{n}=$ distribution index
$\mathrm{a}=$ size coefficient
$d_{0}=$ morphological diameter
$\rho=$ density
$\nabla=$ laplacian
$\alpha=$ volume fraction
$u, u_{l}=$ fluid velocity
$m_{l s}=$ interphase mass transfer
$n_{0}=$ normal unit vector
$r_{a}, r_{b}=$ position vector
$I_{0}=$ moment of inertia
$m_{a}, m_{b}=$ Particle mass
$v_{a}, v_{b}=$ speed vector
$\omega=$ rotation speed vector

$\mathrm{G}=$ particle cumulative percentage

$\mathrm{a}=$ size coefficient

$d_{0}=$ morphological diamete

$\rho=$ density

$\alpha=$ volume fraction

$u, u_{l}=$ fluid velocity

$m_{l s}=$ interphase mass transfer

$n_{0}=$ normal unit vector

$r_{a}, r_{b}=$ position vector

= moment of inertia

$\omega=$ rotation speed vector

$[-]$
$[\mathrm{m}]$
$[-]$
$[-]$
$[\mathrm{m}]$
$\left[\mathrm{kg} / \mathrm{m}^{3}\right]$
$[-]$
$[-]$
$[\mathrm{m} / \mathrm{s}]$
$[-]$
$[-]$
$[-]$
$\left[\mathrm{kg} / \mathrm{m}^{2}\right]$
$[\mathrm{kg}]$
$[\mathrm{m} / \mathrm{s}]$
$[\mathrm{rpm}]$

$[\mathrm{m} / \mathrm{s}]$

$[-]$

$\left[\mathrm{m} / \mathrm{s}^{2}\right]$

$\left[\mathrm{m} / \mathrm{s}^{2}\right]$

[Pa]

[Pa]

$\left[\mathrm{kg} / \mathrm{m}^{2} \cdot \mathrm{s}^{2}\right]$

$[\mathrm{kg} / \mathrm{m} \cdot \mathrm{s}]$

$[\mathrm{kg} / \mathrm{m} \cdot \mathrm{s}]$

[-]

[-]

$[\mathrm{m} / \mathrm{s}]$

$[\mathrm{m} / \mathrm{s}]$

$[\mathrm{N}]$

[-]

$[\mathrm{kg} \cdot \mathrm{m} / \mathrm{s}]$ 


\section{References}

1. Sun, H.H.; Huang, Y.C.; Yang, B.G. Contemporary Cemented Backfilling Technology; Metallurgical Industry Press: Beijing, China, 2002; pp. 113-114.

2. Sommerfeld, M. Modeling of Particle-Wall Collisions in Confined Gas-Particle Flows. Int. J. Multiph. Flows 1998, 18, 905-926. [CrossRef]

3. David, H.; Sebastian, A.; Peter, R. Pipe lining abrasion testing for paste backfill operations. Int. J. Multiph. Flows 2009, 22, 1088-1090.

4. Buffo, A.; Vanni, M.; Marchisio, D.L. Multidimensional population balance model for the simulation of turbulent gas-liquid systems in stirred tank reactors. Chem. Eng. Sci. 2012, 70, 31-44. [CrossRef]

5. Boger, D.V. Rheology of slurries and environmental impacts in the mining industry. Annu. Rev. Chem. Biomol. Eng. 2013, 4, 239-257. [CrossRef] [PubMed]

6. David, A.M.; Alastair, D.S. The effects of a highly viscous liquid phase on vertically upward two-phase flow in a pipe. Int. J. Multiph. Flows 2003, 29, 1523-1538.

7. Zeng, M.; Xu, Z.Q.; Huangfu, J.H.; Liu, J.T.; Zhang, R.Z. Two-phase flow numerical simulation of jet flotation column. J. China Coal Soc. 2008, 33, 795-798.

8. Dykas, S.; Wróblewski, W. Single-and two-fluid models for steam condensing flow modeling. Int. J. Multiph. Flows 2011, 37, 1245-1253. [CrossRef]

9. Thiruvengadam, M.; Zheng, Y.; Tien, J.C. DPM simulation in an underground entry: Comparison between particle and species models. Int. J. Min. Sci. Technol. 2016, 26, 487-494. [CrossRef]

10. Adamczyk, W.P.; Klimanek, A.; Białecki, R.A.; Węcel, G.; Kozołub, P.; Czakiert, T. Comparison of the standard Euler-Euler and hybrid Euler-Lagrange approaches for modeling particle transport in a pilot-scale circulating fluidized bed. Particuology 2014, 15, 129-137. [CrossRef]

11. Ni, C.J.; Lu, G.C.; Zhang, Q.D.; Jing, T.; Wu, J.J.; Yang, L.L.; Wu, Q.F. Influence of core box vents distribution on flow dynamics of core shooting process based on experiment and numerical simulation. China Foundry 2016, 13, 22-29. [CrossRef]

12. Angst, R.; Kraume, M. Experimental investigations of stirred solid/liquid systems in three different scales: Particle distribution and power consumption. Chem. Eng. Sci. 2006, 61, 2864-2870. [CrossRef]

13. Wang, F.; Mao, Z.; Wang, Y. Measurement of phase holdups in liquid-liquid-solid three-phase stirred tanks and CFD simulation. Chem. Eng. Sci. 2006, 61, 7535-7550. [CrossRef]

14. Lee, S.H.; Kim, H.J.; Sakai, E.; Daimon, M. Effect of particle size distribution of fly ash-cement system on the fluidity of cement pastes. Cem. Concr. Res. 2003, 33, 763-769. [CrossRef]

15. González-Tello, P.; Camacho, F.; Vicaria, J.M.; González, P.A. A modified Nukiyama-Tanasaw a distribution function and a Rosin-Rammler model for the particle-size-distribution analysis. Powder Technol. 2008, 186, 278-281. [CrossRef]

16. Foerster, S.F.; Louge, M.Y.; Chang, H.; Allia, K. Measurements of the Collision Properties of Small Spheres. Phys. Fluids 1994, 6, 1108. [CrossRef]

17. Dallavalle, J.M. Micromeritics; Pitman Publishing Corpration: New York, NY, USA, 1948.

18. Syamlal, M. The Particle-Particle Drag Term in a Multiparticle Model of Fluidization; National Technical Information Service: Springfield, VA, USA, 1987; pp. 1353-2373.

19. Richardson, J.R.; Zaki, W.N. Sedimentation and Fluidization: Part I. Trans. Inst. Chem. Eng. 1954, 32, $35-53$.

20. Garside, J.; Al-Dibouni, M.R. Velocity-Voidage Relationships for Fluidization and Sedimentation. Ind. Eng. Chem. Process Des. Dev. 1977, 16, 206-214. [CrossRef]

21. Wu, D.; Cai, S.J.; Yang, W.; Wang, W.X.; Wang, Z. Simulation and experiment of backfilling pipeline transportation of solid-liquid two-phase flow based on CFD. Chin. J. Nonferr. Met. 2012, 22, 2133-2140.

22. Huser, A.; Kvernvold, O. Prediction of sand erosion in process and pipe components. In Proceedings of the 1st North American Conference on Multiphase Technology, Banff, AB, Canada, 10-11 June 1998; Volume 31, p. 217.

(C) 2017 by the authors; licensee MDPI, Basel, Switzerland. This article is an open access article distributed under the terms and conditions of the Creative Commons Attribution (CC-BY) license (http://creativecommons.org/licenses/by/4.0/). 